\title{
Performance Evaluation of Tourism Human Resource Management Based on Fuzzy Data Mining
}

\author{
Fei Wei (iD \\ College of Management, Zhengzhou University of Technology, Zhengzhou, Henan 450044, China \\ Correspondence should be addressed to Fei Wei; 20041025@zzut.edu.cn
}

Received 14 December 2021; Revised 10 January 2022; Accepted 11 January 2022; Published 21 February 2022

Academic Editor: Miaochao Chen

Copyright (C) 2022 Fei Wei. This is an open access article distributed under the Creative Commons Attribution License, which permits unrestricted use, distribution, and reproduction in any medium, provided the original work is properly cited.

\begin{abstract}
Tourism human resources performance management is an important means of enterprise core competitiveness; the assessment results is good or bad will directly affect the staff's work enthusiasm and attitude; the use of tourism human resources, configuration, and performance carries on the scientific, reasonable, and effective comprehensive evaluation and can fully stimulate the potential of employees. To continuously improve the work efficiency, quality, and level of staff, which has certain application value and practical significance for the long-term and healthy development of tourism industry, this article analyzes the current situation of tourism human resource performance management, introduces the data mining technology and fuzzy data mining technology, and then gives the fuzzy data mining algorithm and detailed fuzzy data mining steps, through the fuzzy data mining technology to evaluate the performance of tourism human resource management. It also analyzes the key factors and existing problems of human resource management in tourism industry and puts forward innovative thinking countermeasures for the performance management of human resources in the tourism industry.
\end{abstract}

\section{Introduction}

Tourism is a typical labor-intensive service enterprise, with strong pull effect, persistence, high dependence, and regional differences. Human resource management is the most important source of core competitiveness of tourism, which has an important and long-term impact on the future development of tourism [1-3]. At present, although China's tourism industry has begun to take shape in terms of quantity, there are still many problems in human resource management, especially in the input and output of human resources, such as the low quality of employees, lack of high-level compound talents, and poor business performance. In particular, the imbalance between the growth number of tourism enterprises and the proportion of personnel supply is serious, and the phenomenon of brain drain has been plaguing the tourism industry. Specific reasons mainly include the following: firstly, the management personnel have insufficient understanding of the importance of human resource management and lack of systematic human resource planning. The responsibilities of many tourism posts are not clearly defined, the personnel allocation is unreasonable, the personnel quality is not high, and the reserve talent is insufficient. When human resources become the bottleneck of enterprise development, they rush to recruit and train. secondly, it emphasizes institutionalized management, ignores the spiritual needs of employees, tends to attract and retain talents with higher material rewards, but does not attach importance to people-oriented, and motivates employees with promotion, honor, and other aspects. Thirdly, the salary structure is unreasonable, the salary level is low, the salary system is not competitive, especially for the salary of management, and technical personnel are not consistent with their contributions and does not play a due incentive role; finally, the lack of scientific selection means and the neglect of staff career development make the frequent loss of staff and difficult to retain talents. Therefore, the efficiency of human resources has become the focus of tourism, and how to improve the efficiency of human resource management has become a widespread concern [4-6]. 
The performance evaluation of tourism human resource management is not only directly related to the rational allocation of personnel, but it also plays an important role in realizing the optimization of enterprise resources [7]. The problem of low performance of the tourism industry is increasingly exposed, and one of the important reasons is the lack of scientific enterprise performance evaluation ideas and methods. Human resources performance appraisal is a management and appraisal method formulated by enterprises for employees. It presents three characteristics: comprehensiveness, systematicness and complexity. It is mainly to effectively restrict employees' work consciousness, behavior and efficiency, fully stimulate and mobilize employees' enthusiasm, initiative and creativity, and through a series of specific and feasible quantitative indicators, The measurement process of performance appraisal for employees' working status, performance, behavior, consciousness, and performance [8-10]. High quality and high-level human resource management performance appraisal not only helps enterprises improve the overall work efficiency and level of employees, but also helps enterprises attract and retain more high-quality talents, but also helps to ensure the rationality of employees' salary. At present, the performance appraisal of human resource management in tourism industry mainly has the following problems: first, there is a lack of enough attention to the performance appraisal and does not operate in strict accordance with the relevant indicators. In the performance appraisal and evaluation, they often add their own subjective feelings and basic impressions of employees, which is easy to lead to the formality of performance appraisal. Secondly, the quality of performance appraisal needs to be improved. Human resource performance appraisal does not carry out objective and comprehensive analysis on the evaluation of other employees, and the management mode and concept are relatively backward, and the assessment mode is also relatively closed, which deviates from the requirements of objectivity and comprehensiveness of appraisal. Finally, there is no timely and effective feedback on performance appraisal. In order to ensure the timeliness and value of appraisal results, timely and effective feedback on performance appraisal results is necessary to help enterprise managers have a comprehensive understanding of the working status of employees, and then formulate effective reward and punishment measures $[11,12]$.

With China's entry into WTO, the competition for talents is becoming increasingly fierce, so the performance management of tourism employees is particularly important. In the whole process of human resource management of the tourism industry, performance appraisal has a direct impact on employees' salary and job changes, and provides a basis for employees' training. Therefore, fuzzy data mining technology can be used to extract relevant information from the database of employees' working conditions, find the connections and patterns, and classify the types of employees, so that employees can compete in a fair and just environment and improve their performance, so as to enhance the competitiveness of tourism.

\section{Methods and Models of Tourism Human Resource Management Performance Evaluation}

At present, most tourism enterprises lack a complete performance management system, and many tourism enterprises still remain in the stage of performance assessment. Some small tourism enterprises even do not establish performance system or specific performance evaluation indicators, which greatly affects the effect of human resource management in tourism [13-15]. Performance management cannot play a good role in evaluation, supervision, and guidance, affecting the rapid and healthy development of tourism [16]. Enterprise performance evaluation includes two aspects of the evaluation of enterprise management benefit and enterprise management performance, with multifactor, multidimension, and dynamic characteristics and factors such as the emotion and quality of the examiners [17]. "360 all-round assessment method" and "KPI core assessment method" are two common methods for the tourism industry to evaluate human resource performance management.

"360 all-round assessment method" is also known as "allperspective assessment," which is the most widely used human resource performance management method in the tourism industry. The basic approach is to make systematic evaluation and theoretical consideration of the tourism industry leaders, colleagues, and tourists on the evaluators themselves and formulate corresponding performance parameters for the evaluators based on the coefficient of evaluation and consideration. As most of the anonymous evaluation is adopted, there are some loopholes in the reliability and reference of this anonymous evaluation [18]. Of course, the advantage of " 360 all-round assessment method" is that it can provide a reference for the human resource performance management of the tourism industry from all aspects and angles.

"KPI core assessment method" provides important indicators for tourism human resource management departments to formulate performance management. The core of this method is that the tourism industry can centrally extract key and safe key indicators from numerous performance assessments. It is an innovation of human resource performance management method for enterprise leaders to make self-evaluation by writing debriefing report. For those who participate in the evaluation, writing the reporting report can not only effectively summarize the work performance and work ability of the examinee during the evaluation, so that the employees can fully understand their job responsibilities and goals [19]. In the long run, it can promote the long-term development of enterprises. Finally, the supervisor is responsible for the performance interview of subordinates, which is also an important means of human resource performance management of tourism enterprises themselves. At the same time, the human resources department should be responsible for collecting and summarizing all evaluation results, correcting the deviation in evaluation, and finally realizing the optimal allocation of human resources performance management. 
In this article, Battese \& Coelli model in the random preface analysis method is used to analyze the efficiency and influencing factors of tourism human resources. Following the principles of scientific, comparable, targeted, and feasible and considering the performance, ability, attitude, and applicability of employees, the following input-output variables are set.

Variables of human resource input: the investment of tourism companies in human resources mainly includes labor force input and capital input, among which labor force input includes the input of quantity and quality of workers, the quantity of workers refers to the total number of all employees, and the quality of workers includes age, education level, training, and development level. The capital input of enterprises to human resources generally refers to the cost of human resources, which is mainly composed of the acquisition, development, use, guarantee, and replacement of human resources. The quantity and quality of workers and the cost of human resources constitute the main input factors of human resources in tourism companies. According to the principle of data availability and simplification, the total number of employees is selected as one of the input variables in terms of the number of workers. In terms of the quality of labor, the proportion of employees with junior college or above is selected as one of the input variables. In terms of the cost of human resources, per capita education and training funds and per capita salary are selected as one of the input variables [20].

Human resource output variables: enterprise investment reflected in the output of human resources is for enterprises to create value; generally speaking, the travel company should include two parts of the economic and social benefits of output, but common social benefits cannot be directly measured; to carry out quantitative calculation, this article choose the enterprise economic benefit, namely, enterprise performance index as the output variables of human resources. Operating income or net profit is taken as an indicator to measure enterprise performance. Based on the principle of comparability, in order to avoid horizontal interference factors caused by different company sizes, relative data are taken for this variable, and per capita operating income, that is, total labor productivity, is used as the variable of human resource output.

Selection of influencing factor variables: there are many factors that affect the human resource efficiency of listed tourism companies. The macrolevel includes national policies, social and economic environment, industry development, and other environmental factors, and the medium level includes enterprise size, organizational structure, culture, strategy, rules and regulations, and other enterprise factors [21]. At the microlevel, it includes human resource management factors such as employee quality, employee development degree, and employee potential development degree. The influencing factors of human resource efficiency selected in this article mainly include the following variables: the proportion of education and training funds in total compensation, the proportion of employee compensation in operating revenue, the proportion of executive compensation in total compensation, and the proportion of fixed assets and employee expenses in total cost per capita. The selection of variables for the performance evaluation of tourism human resource management is listed in Table 1.

According to the variables of output per unit of four inputs in Table 1, this article builds an evaluation model of tourism human resource efficiency and its influencing factors on the basis of Battese \& Coelli model. The production function is as follows:

$$
\begin{aligned}
\ln Y_{\text {it }}= & \beta_{0}+\beta_{1} \ln x_{1 \mathrm{it}}+\beta_{2} \ln x_{2 \mathrm{it}}+\beta_{3} \ln x_{3 \mathrm{it}} \\
& +\beta_{4} \ln x_{4 \mathrm{it}}+V_{i t}-U_{\mathrm{it}},
\end{aligned}
$$

where $Y$ is the labor productivity of the whole staff, $x_{1}-x_{4}$ is the total number of employees, the proportion of employees with junior college degree or above, per capita education and training funds, and per capita salary, respectively; $i=1,2, \ldots, 30$ is the sequence number of the sample company, $t=1,2, \ldots, 5$ is the period number, $\beta_{0}$ is the intercept item; $\beta_{1}-\beta_{4}$ are coefficients to be estimated, $V_{\text {it }}$ is random error terms, and $U_{\text {it }}$ is nonnegative technical inefficiency terms.

The technical inefficiency function is as follows:

$U_{\text {it }}=\delta_{0}+\delta_{1} z_{1 \mathrm{it}}+\delta_{2} z_{2 \mathrm{it}}+\delta_{3} z_{3 \mathrm{it}}+\delta_{4} z_{4 \mathrm{it}}+\delta_{5} z_{5 \mathrm{it}}+W_{\mathrm{it}}$,

where $z_{1}-z_{5}$ is the influencing factor variable that leads to the difference of human resource efficiency between samples, which are the proportion of education and training funds in total salary, the proportion of employee salary in operating income, the proportion of executive salary in total salary, and the proportion of per capita fixed assets and employee expenses in total cost, $\delta_{0}$ is the intercept term, $\delta_{1}-\delta_{5}$ is a set of the estimated coefficient, and $W_{\text {it }}$ is a random error term.

The technical efficiency status is as follows:

$$
\mathrm{TE}_{\mathrm{it}}=\exp \left(-U_{\mathrm{it}}\right)
$$

where $\mathrm{TE}_{\mathrm{it}}$ represents the human resource efficiency level of the first company in the first period. If $U_{\text {it }}=0$, it is in the state of technical efficiency; If $U_{\text {it }}>0$, it is in the state of technical inefficiency.

The calculation of the variation rate is as follows:

$$
\gamma=\frac{\sigma_{u}^{2}}{\left(\sigma_{u}^{2}+\sigma_{v}^{2}\right)} .
$$

Here, $\gamma \in[0,1]$; its function is mainly used to test the rationality of the model.

\section{Fuzzy Data Mining Algorithm}

3.1. Data Mining Algorithm. Data mining is a new research field with great potential, which integrates database, artificial intelligence, machine learning, statistics, and other disciplines. Different from traditional data analysis, the information obtained has three characteristics: unknown, validity, and practicality. It is from a large number of noisy, incomplete, random, and fuzzy databases or data warehouses, through data processing means, to find and extract implicit, unknown, nontrivial, and potentially valuable information or patterns, help decision makers find potential 
associations, characteristics, and trends among data, find neglected elements, and predict the future and decisionmaking behavior. There are three steps: data preparation, law search, and law representation [22-24]. A typical data mining system is shown in Figure 1, which includes the following six main components:

(1) Data Source. Consisting of one or a series of databases, data warehouses, other information repositories, or spreadsheets. This data can be cleaned up and integrated.

(2) Database or Data Warehouse Server. Responsible for extracting the data meets the demand.

(3) Knowledge Base. This is domain knowledge and may include conceptual layering. User belief knowledge can also be included to assess the model's interest in terms of unexpectability.

(4) Data Mining Engine. This is an essential part of a data mining system and ideally consists of a set of functional modules for performing.

(5) Model Evaluation. Integrated with a data mining module to filter discovered patterns using a measure of interest. It is recommended to embed pattern evaluation interest as deeply as possible into the data mining process in order to focus the search on interesting patterns.

(6) User Interface. Communication between users and data mining systems.

3.2. Fuzzy Data Mining Algorithm. However, pure data mining may lead to problems such as "sharp edges" [25]. In recent years, fuzzy set theory has been used more and more in intelligent systems because of its brevity and similarity to human reasoning. Data mining integrated with fuzzy theory can discover more general and important knowledge and rules from data. Therefore, fuzzy data mining is applied in more and more fields and has achieved good results. Therefore, the fuzzy data mining technology combining fuzzy logic and data mining is considered to be introduced into the performance evaluation of tourism human resource management. Fuzzy data mining technology can predict the future trend and behavior, so as to support enterprise management decision. The fuzzy data mining algorithm is applied to cluster complex customer requirements reasonably, which fully reflects the matching degree and completeness between customer requirements and product modules.

The main algorithms for fuzzy data mining are as follows: fuzzy association rules, fuzzy calibration recognition, fuzzy classification, and fuzzy cluster analysis. The essential difference between fuzzy data mining and traditional data analysis is that it uses the fuzzy mining algorithm and data extracted from data warehouse to mine information [26]. The specific steps are as follows:

\subsubsection{Pattern Discovery}

(1) Establish a sample set $U=\left\{u_{1}, u_{2}, \ldots, u_{n}\right\}$.

$$
u_{i}=\left(u_{i 1}, u_{i 2}, \ldots, u_{\mathrm{im}}\right), \quad(i=1,2, \ldots, n) .
$$

Tt should be the original data standardization, and find out its average, first sample set consists of a sample, for example, a certain indicators of $n$ sample data, can take $n$ to type in the first sample $k$ of the first indicators data $u_{1 k}^{\prime}, u_{2 k}^{\prime}, \ldots, u_{n k}^{\prime}$. Their average value is calculated as follows:

$$
\begin{aligned}
u_{i k}^{\prime} & =\frac{\left(u_{1 k}^{\prime}+u_{2 k}^{\prime}+\cdots+u_{n k}^{\prime}\right)}{n} \\
& =\frac{1}{n} \sum_{i=1}^{n} u_{i k}^{\prime}, \quad k=1,2, \ldots, m .
\end{aligned}
$$

Then, the standard deviation $S_{k}$ of these original data can be calculated as follows:

$$
S_{k}=\sqrt{\frac{1}{n} \sum_{i=1}^{n}\left(u_{i k}^{\prime}-u_{k}^{\prime}\right)^{2} .}
$$

Then, the standardized value $u_{i k}^{\prime \prime}$ of each data can be calculated as follows:

$$
u_{i k}^{\prime \prime}=\left|\frac{u_{i k}^{\prime}-u_{k}^{\prime}}{S_{k}}\right| .
$$

At this time, the standardized data $u_{i k}^{\prime \prime}$ obtained may not all fall into the closed interval $[0,1]$.

$$
u_{\mathrm{ik}}=\frac{u_{i k}^{\prime \prime}-u_{\min k}^{\prime \prime}}{u_{\max k}^{\prime \prime}-u_{\min k}^{\prime \prime}}
$$

where $u_{\max k}^{\prime \prime}$ and $u_{\min k}^{\prime \prime}$ represent the maximum value and minimum value of $u_{1 k}^{\prime \prime}, u_{2 k}^{\prime \prime}, \ldots, u_{n k}^{\prime \prime}$.

(2) Establish analogical relationship. The general form is as follows:

$$
R=\left(\begin{array}{cccc}
r_{11} & r_{12} & \cdots & r_{1 n} \\
r_{21} & r_{22} & \cdots & r_{2 n} \\
\vdots & \vdots & \vdots & \vdots \\
r_{n 1} & r_{n 2} & \cdots & r_{n n}
\end{array}\right) \quad \begin{aligned}
& 0 \leq r_{i j} \leq 1, \\
& i=1,2, \ldots, n, \\
& j=1,2, \ldots, n .
\end{aligned}
$$

There are many calculation methods; here, the most valuable method is adopted, namely,

$$
r_{i j}=\frac{\sum_{k=1}^{n} \min \left(u_{i k}, u_{j k}\right)}{\sum_{k=1}^{n} \max \left(u_{i k}, u_{j k}\right)}, \quad i, j \leq n .
$$

(3) Cluster Analysis. When $r_{i j} \neq 0$, vertices $i$ and $j$ can be connected to an edge. The specific approach is to draw a vertex set of a point $i$, and then according to the order from the largest to the and it is required not to generate a loop until all vertices are connected, so as to get a maximum tree. To be more precise, it is a "weighted" tree, in which each edge can be assigned a weight, that is, $r_{i j}$. But because of the specific 
TABLE 1: Selection of variables for performance evaluation of tourism human resource management.

\begin{tabular}{|c|c|c|c|c|}
\hline Variable types & Code & Name & Computational formula & Unit \\
\hline Output variable & $\mathrm{Y}$ & Labor productivity of total workers & $\begin{array}{c}\begin{array}{c}\text { Current year operating revenue/total number of } \\
\text { employees }\end{array} \\
\text { em }\end{array}$ & $\begin{array}{l}\text { Yuan/ } \\
\text { person }\end{array}$ \\
\hline \multirow{3}{*}{ Input variables } & $\mathrm{X} 1$ & Size of entire staff & $\begin{array}{l}\text { The number of all permanent employees in a } \\
\text { company }\end{array}$ & Person \\
\hline & $\mathrm{X} 2$ & $\begin{array}{c}\text { Proportion of employees with junior } \\
\text { college or above }\end{array}$ & $\begin{array}{c}\text { Number of employees with college degree or above/ } \\
\text { total number of employees }\end{array}$ & \multirow{4}{*}{$\begin{array}{l}\text { Yuan/ } \\
\text { person }\end{array}$} \\
\hline & $\mathrm{X} 3$ & $\begin{array}{c}\text { Per capita expenditure on education and } \\
\text { training }\end{array}$ & $\begin{array}{l}\text { Total education and training funds for employees/ } \\
\text { total number of employees this year }\end{array}$ & \\
\hline \multirow{5}{*}{$\begin{array}{l}\text { Influencing factor } \\
\text { variables }\end{array}$} & $\mathrm{Z} 1$ & $\begin{array}{l}\text { Proportion of education and training } \\
\text { funds in total remuneration }\end{array}$ & $\begin{array}{l}\text { Education and training expenses/total remuneration } \\
\text { for the current year }\end{array}$ & \\
\hline & $\mathrm{Z} 2$ & $\begin{array}{l}\text { Employee compensation as a percentage } \\
\text { of revenue }\end{array}$ & $\begin{array}{c}\text { Total compensation/total operating revenue for the } \\
\text { current year }\end{array}$ & \\
\hline & $\mathrm{Z3}$ & $\begin{array}{c}\text { Executive compensation as a percentage } \\
\text { of total compensation }\end{array}$ & $\begin{array}{c}\text { Total executive compensation/total compensation for } \\
\text { the year }\end{array}$ & \multirow{3}{*}{$\begin{array}{l}\text { Yuan/ } \\
\text { person }\end{array}$} \\
\hline & $\mathrm{Z} 4$ & Fixed assets per capita & $\begin{array}{c}\begin{array}{c}\text { Year-end net value of fixed assets/total number of } \\
\text { employees }\end{array}\end{array}$ & \\
\hline & $\mathrm{Z5}$ & $\begin{array}{c}\text { Employee expenses as a percentage of } \\
\text { total costs }\end{array}$ & $\begin{array}{c}\begin{array}{c}\text { Year-end net value of fixed assets/total number of } \\
\text { employees }\end{array}\end{array}$ & \\
\hline
\end{tabular}

Note. The blank space in the unit column is expressed as percentage, without unit.

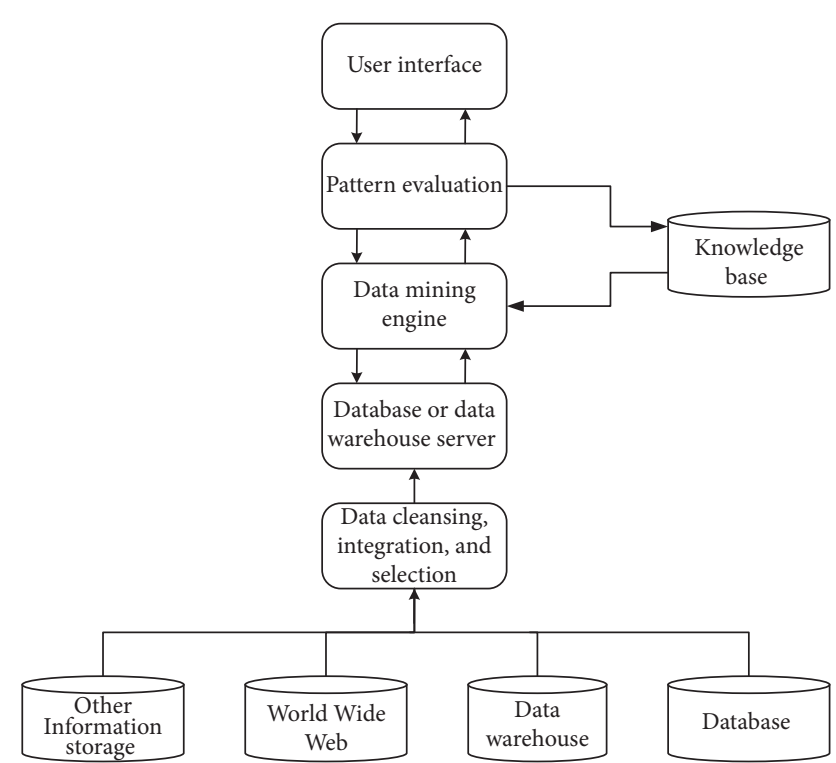

Figure 1: Typical data mining system structure.

connection, this biggest tree is unlikely to be unique [27-29]. Then, cut off the maximum number $\lambda$; that is, remove the edges of those weights $r_{i j}<\lambda$, so that the tree is cut into complementary word trees. Although the maximum tree is not unique, the subtrees obtained are all the same after the truncation.

\subsubsection{Prediction}

(1) Calculate the average index of each mode. For each model obtained, the average index is calculated as follows:

$$
\operatorname{Mode}_{i j}=\sum \frac{u_{k j}}{p} \quad i=1,2, \ldots, s j=1,2, \ldots, m .
$$

(2) Prediction

The sample $X=\left(X_{1}, X_{2}, \ldots, X_{n}\right)$ to be predicted is $n$ fuzzy subset of the sample in the domain $U$, and the matching progress between them is calculated:

$$
(X, \text { Mode })=\left(\frac{1}{2}\right)\left[X \cdot \text { Mode }_{i}+\left(1-X \odot \text { Mode }_{i}\right)\right],
$$

where $\cdot$ and $\odot$ represent inner product and outer product in fuzzy operation, respectively [30-32].

According to the principle of proximity, namely,

$$
\begin{aligned}
& (X, \text { Mode })=\max \left(\left(X, \text { Mode }_{1}\right),\right. \\
& \left.\left(X, \text { Mode }_{2}\right), \ldots,\left(X, \text { Mode }_{s}\right)\right) .
\end{aligned}
$$

\section{Results Analysis and Discussion}

In human resource management activities, performance appraisal is the bridge of human resource management. It connects the actual work situation of employees in the enterprise with the goal of the enterprise, adjusts the work behavior of employees at any time through performance appraisal, and provides the basis to improve the work efficiency of employees. There are many standards for employee performance appraisal. Here, we choose the four standards that most enterprises often adopt: work task, work quality, work skills, and work attitude. Select 10 objects to be divided from the data warehouse. The specific clustering classification is shown in Figure 2:

(1) The standardized matrix is obtained, and then, the normalized matrix is obtained.

(2) Establish a fuzzy similarity matrix by max and min method.

(3) The maximum tree method is adopted to conduct cluster analysis as shown in Figure 3. 

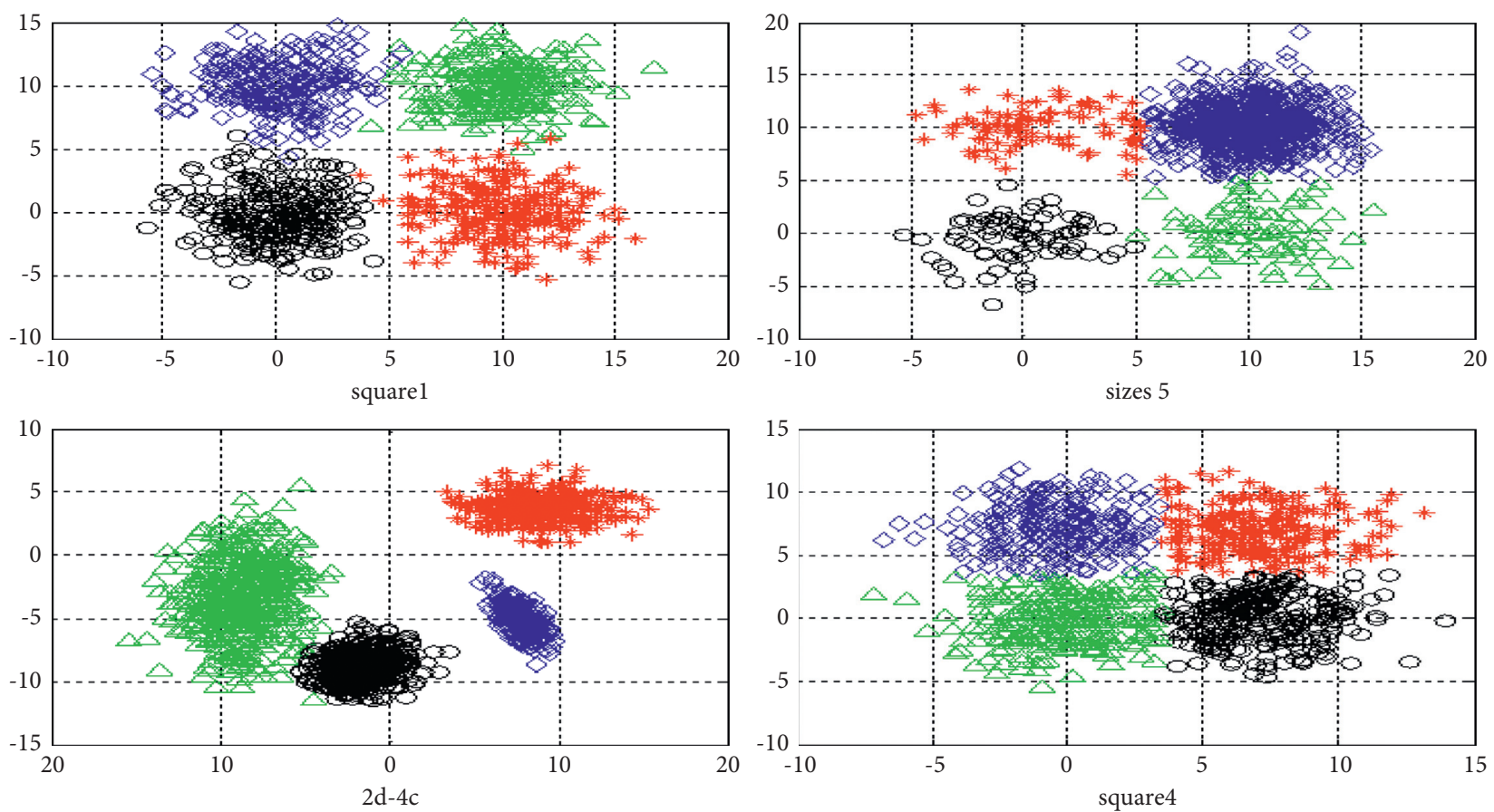

FIgURE 2: Specific clustering classification.

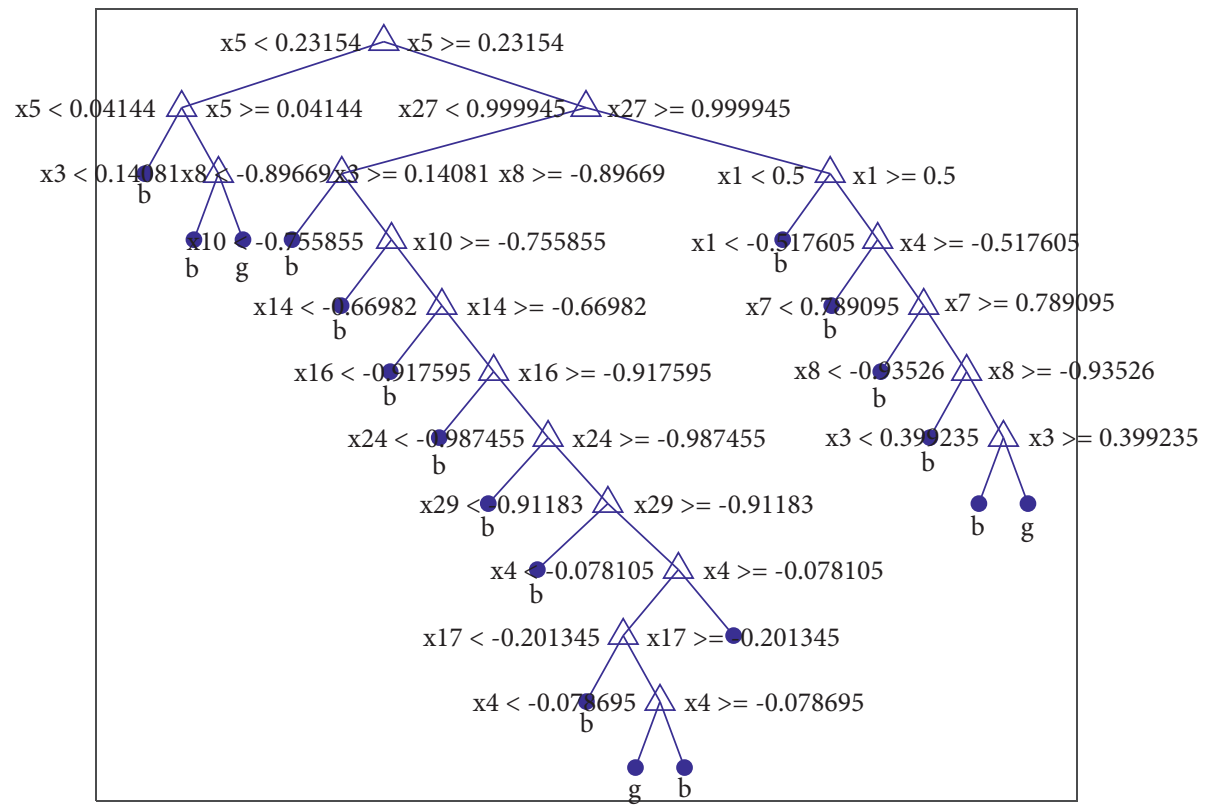

Figure 3: The biggest tree generation process.

(4) According to different nine values, different modes can be obtained. If $\lambda=0.53$, four modes are obtained; that is, employees are divided into four types.

Comparing the current value and potential value of customers, it can be seen that the final transformation of potential value of bank customers into revenue value is an uncertain quantity, so the selection of customer value should focus more on the current value. Therefore, this paper selects the value after the sum of current value as the basis for clustering and subdividing customer value, and the added type A customers are high-value customers, type D customers are potential value customers, type $\mathrm{C}$ customers are general value customers, and type B customers are low value customers. Although such customers account for a relatively small proportion of the bank's individual customers, they account for most of the bank's profits. Although they account for a relatively small proportion of tourism revenue, 


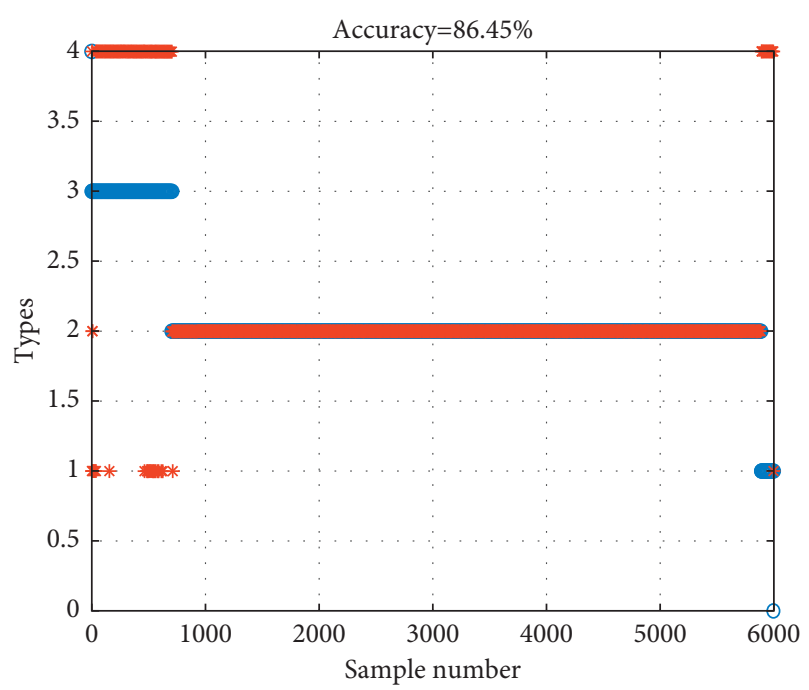

- Actual intrusion types

* Kmeans clustering types

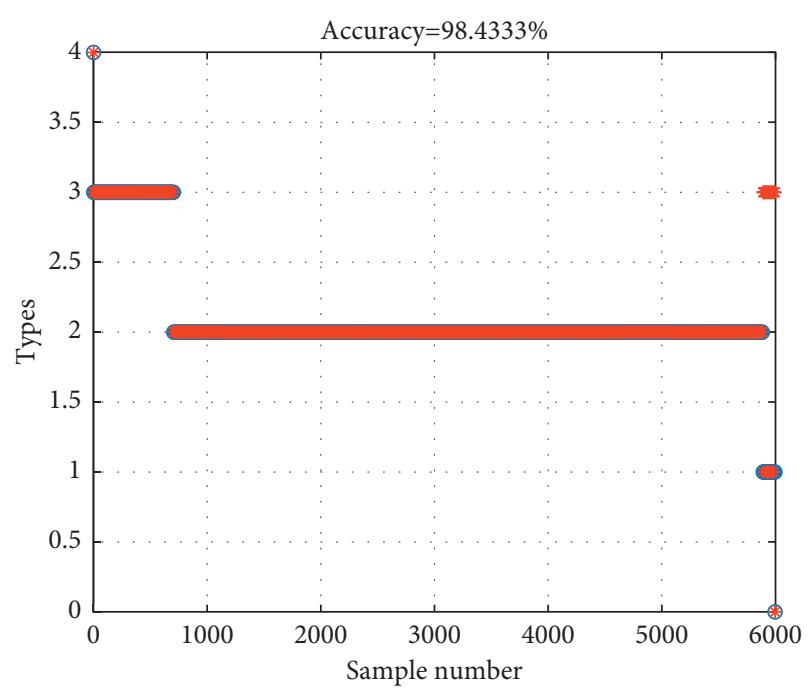

- Actual intrusion types

* KNN clustering types

FIgURE 4: Comparison of two kinds of clustering classification results.

they account for the majority of tourism performance. The classification results of two clusters are shown in Figure 4.

In fact, the performance evaluation of the tourism industry is the result of its input-output ability, competitive ability, and management ability acting on the specific tourism resources of the enterprise. To measure the performance improvement level of tourism enterprises, we should not only examine the final result of the enterprise in a certain period, but also examine the amount of resource input and resource quality grade of the enterprise in this period, and compare the result and input of the enterprise, so as to make horizontal and vertical comparison. For example, enterprise $\mathrm{A}$ has 10 million yuan of total assets, obtained in 2004: business income of RMB 1 million; enterprise B has RMB 1 million: assets and 200,000 days of business income in the same year. If the actual income is only compared, enterprise A is 5 times that of enterprise B, that is, $100 / 20=5$ times. However, if the input-output comparison is conducted, enterprise $A$ is only $1 / 2$ that of enterprise $B$, that is, $(100 / 1000) /(20 / 100)=1 / 2$. If we consider the difference in resource composition and quality between the two enterprises, this method is not applicable. The data prediction results of fuzzy data mining are shown in Figure 5. The human resource management performance evaluation index grade coding results are shown in Figure 6.

It was proved that controllable technical inefficiency accounted for $84.97 \%$ of the random error, indicating that the main reason for the difference in efficiency value was technical inefficiency, and the model was reasonable. The unilateral letter report (LR) test value of the model is 183.6989 , which is larger than the critical value of mixed $\chi^{2}$ distribution at $1 \%$ level with 7 degree of freedom. Therefore, the rationality of the model is proved by the LR test. In addition, among the 11 coefficients to be estimated, 7 parameters pass the $T$ test, indicating that their corresponding independent variables have a significant impact on the dependent variable. $\sigma 2$ represents the portfolio variance, which can pass the $1 \%$ significance test to illustrate the level of inefficiency in the sample of 30 firms. The variation rate $\gamma$ also passed the significance test of $1 \%$. Since sales force automation (SFA) does not require all parameters to pass the $T$ test and the model has passed the LR test, it can be considered that it is scientific and reasonable to use SFA model to measure the human resource efficiency of listed tourism companies. Neighbor connections and weight distances are shown in Figure 7. Neighbor planes are shown in Figure 8.

The mean value of human resource efficiency of companies with large fluctuations in the five-year period is lower, whereas that of companies with small fluctuations is higher. China's tourism industry still has a good effect of material incentives, and training efforts are insufficient. In the analysis of influencing factors, employee compensation, enterprise scale, human resource quantity, quality, and development degree, enterprise's management level helps to improve the efficiency of human resources, and although employee expenses have a negative impact on the efficiency of human resources, they can help to improve the service ability of employees under reasonable control. In addition, the analysis results of influencing factors also show that the human resource efficiency of the tourism industry is related to the business type of the company and has no direct relationship with the economic development degree of the region. Therefore, companies with different business types should improve their human resource efficiency from their own perspective. What employees care most about is whether the implementation of performance management can increase salary and welfare. As many as $70 \%$ of the surveyed employees think salary and welfare is the most important aspect, $20 \%$ think personal development is the most important aspect, and only $10 \%$ think fairness and rationality is the most important factor for them to carry out performance management. Data mining weight positions and sample hits are shown in 

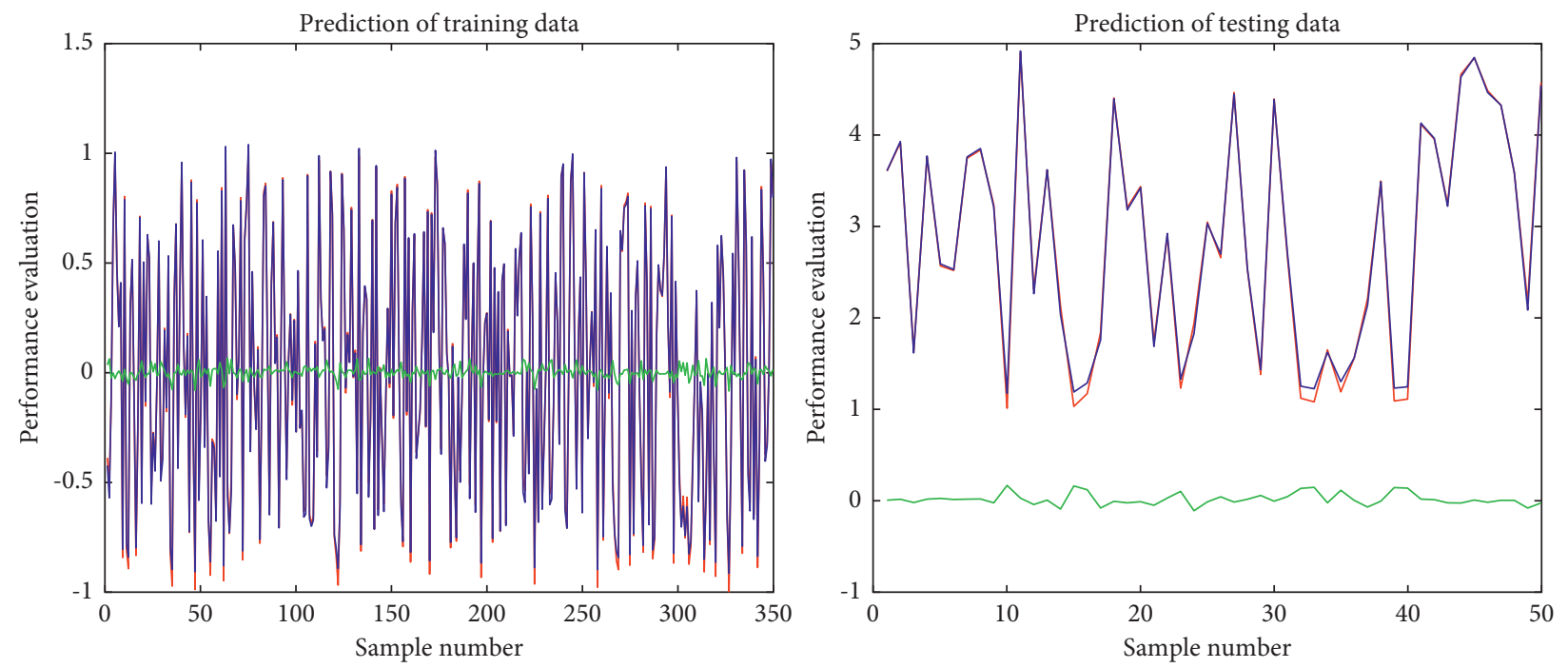

Figure 5: Data prediction results of fuzzy data mining.
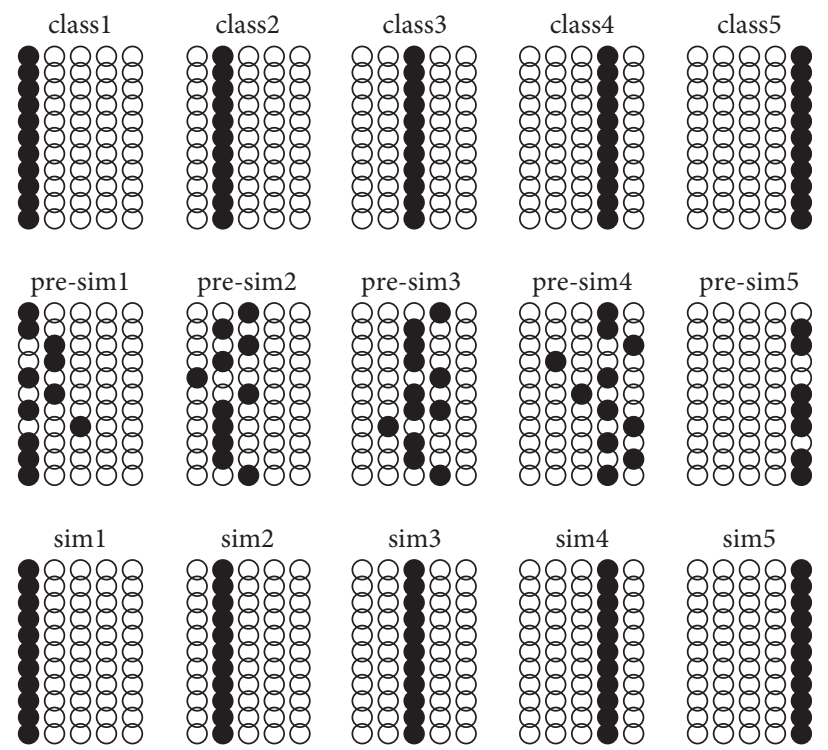

FIGURE 6: Human resource management performance evaluation index grade coding results.
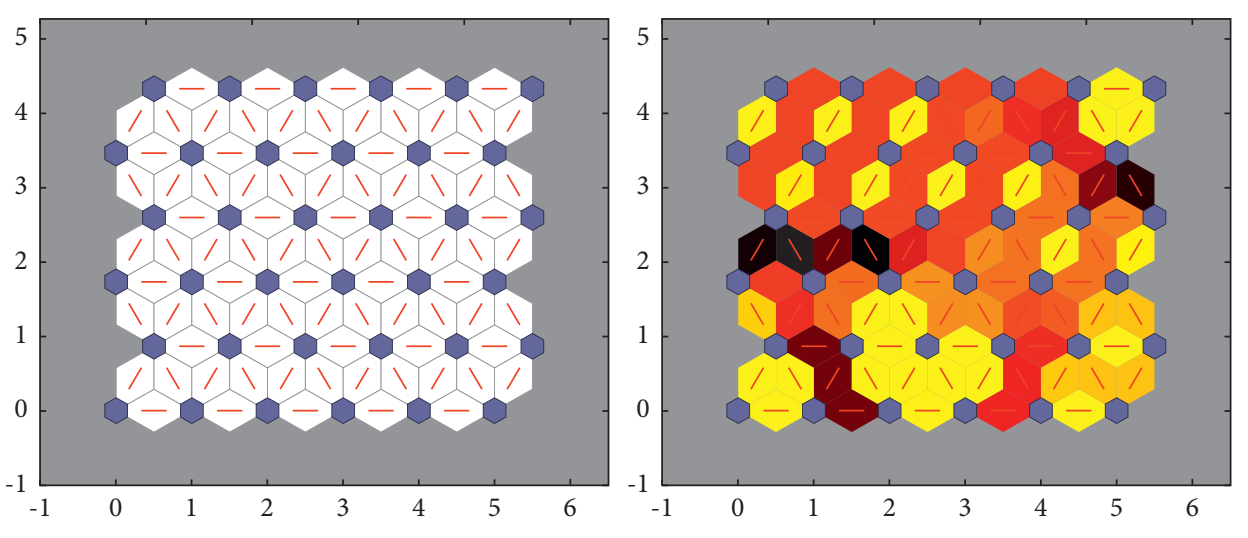

Figure 7: Neighbor connections and weight distances. 

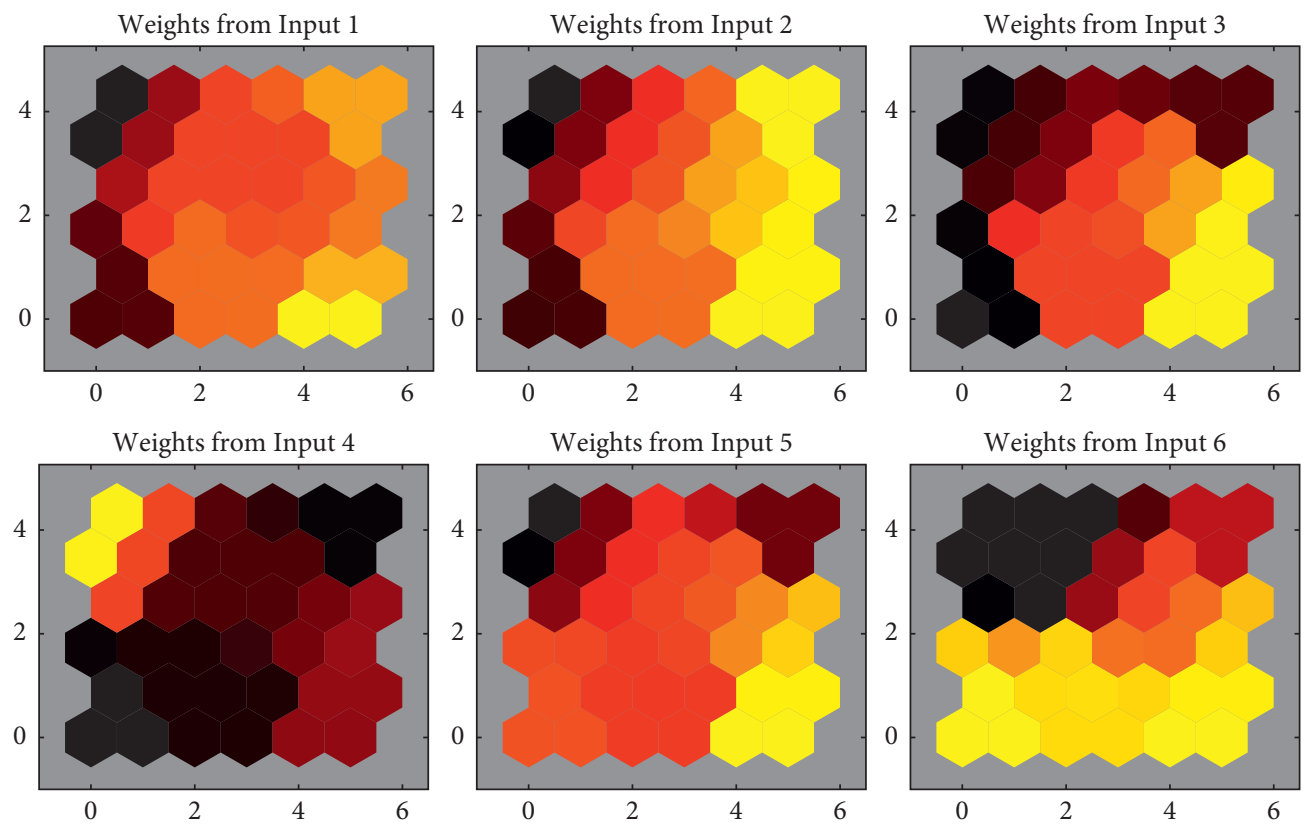

Figure 8: Input planes.
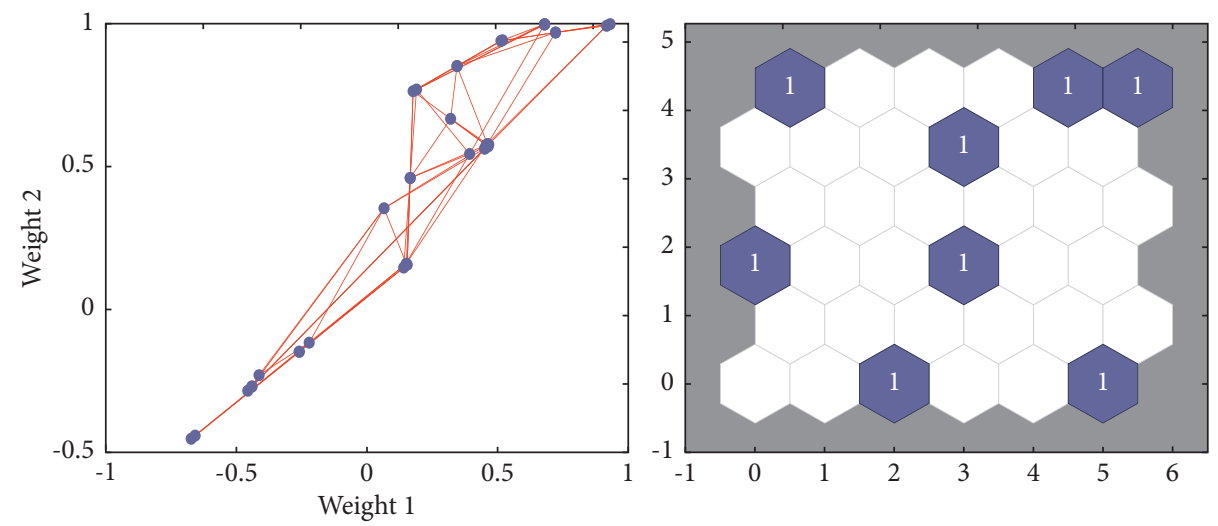

FIGURE 9: Data mining weight positions and sample hits.

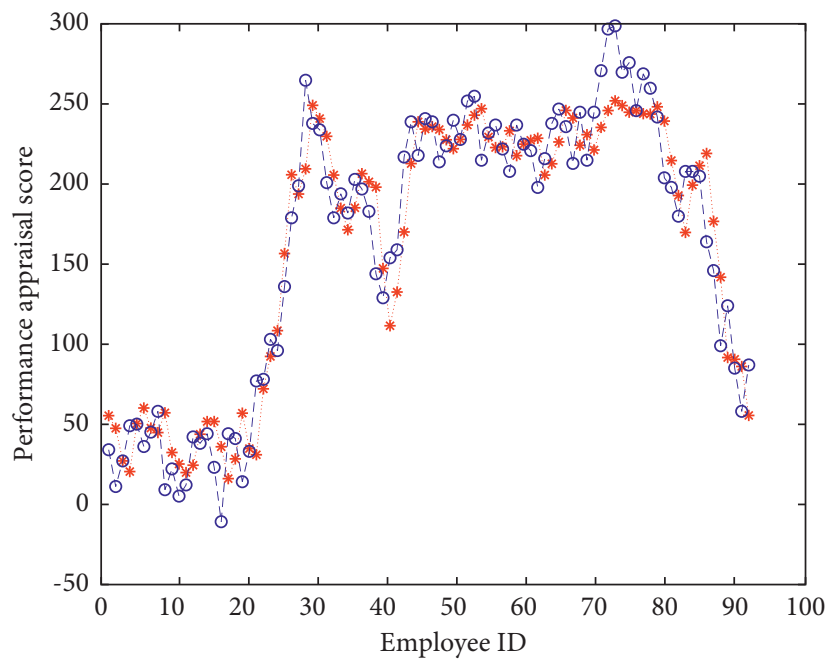

. *.. Prediction score

- $\ominus$ - Actual score

Figure 10: Comparison between fuzzy data mining algorithm prediction and actual situation. 
Figure 9. Comparison between fuzzy data mining algorithm prediction and actual situation is shown in Figure 10.

\section{Conclusion}

In order to make the talents of tourism enterprises get up, stay, attract, and use well, how to reduce the personnel turnover rate of tourism enterprises has become an important topic that must be paid attention to the human resource management of tourism enterprises. Data mining can discover the talent patterns and laws within the organization, which plays a very important role in the talent decision-making and talent planning of tourism industry decision-makers. Performance management as an important part of human resource management in tourism enterprises, the perfect performance management system, and the positive working attitude of the staff will certainly bring new development opportunities to tourism enterprises. Using fuzzy data mining technology, this paper can carry out cluster analysis on the existing employees in the tourism industry, so as to guide the performance evaluation of employees, help decision-makers to carry out talent planning, and put forward the following countermeasures and suggestions to improve the efficiency management level of human resources in the tourism industry, so as to continuously improve the ability and level of human resources performance evaluation of enterprises. Give full play to the important role of human resources in the sustainable development of tourism, in order to promote the overall rapid development and progress of tourism enterprises:

(1) Improve the enterprise human resource performance management system: the tourism industry has a complete human resource performance management system, which not only directly affects the construction of enterprise human resource performance management, but also plays an important role in promoting the actual operation of the enterprise. A complete set of human resource performance management methods can not only fully reflect the core competitiveness of tourism enterprises, but also attract more technical talents related to human resources for the enterprise and promote the long-term development of the enterprise. The establishment of a complete set of human resource performance management system not only requires the enterprise to do enough basic work of human resource performance management, but also requires the enterprise to systematically divide the responsibilities of each department and employees.

(2) Set up a scientific performance assessment and evaluation system: the tourism industry should set up a scientific and reasonable assessment system, which is closely related to the assessment results. The assessment results of tourism enterprises should take the formulation of reasonable assessment indicators as a reference, comprehensively consider the characteristics of employees and the development direction of enterprises, and have a complete assessment system, which can not only promote the establishment of human resources performance management system but also directly affect the management level of enterprises. Human resource managers should clarify specific objectives, that is, what is the purpose of salary communication, what methods are adopted, and what effects are to be achieved.

(3) Strengthen performance communication and create a good enterprise atmosphere: on the one hand, managers improve their management level and organizational performance by constantly discovering and solving problems. On the other hand, in the process of implementing performance plans, employees can understand the implementation of performance plans through communication, analysis, and guidance, so as to control the factors affecting the completion of performance goals in advance and eliminate interference. Performance management is the task of all people in an enterprise. Let managers and employees participate in it personally, accept it from the heart, and implement it physically, so as to achieve the expected effect of performance management.

\section{Data Availability}

The data used to support the findings of this study are available from the corresponding author upon request.

\section{Conflicts of Interest}

The author declares that there are no conflicts of interest.

\section{Acknowledgments}

This work was supported by the Key Research and Development and Promotion Special Project of Henan Province (project title: Research on the Financial Policy System of Reducing Cost and Increasing Efficiency of Henan Entity Enterprises in the New Era), under Grant no. 212400410526.

\section{References}

[1] K. Alexiou and J. Wiggins, "Measuring individual legitimacy perceptions: scale development and validation," Strategic Organization, vol. 17, no. 4, pp. 470-496, 2019.

[2] S. Banerjee and S. Venaik, "The effect of corporate political activity on MNC subsidiary legitimacy: an institutional perspective," Management International Review, vol. 58, no. 5, pp. 813-844, 2018.

[3] J. Barrena-Martinez, M. López-Fernández, and P. M. RomeroFernández, "The link between socially responsible human resource management and intellectual capital," Corporate Social Responsibility and Environmental Management, vol. 26, no. 1, pp. 71-81, 2019.

[4] J. Y. Chung, B. K. Berger, and J. DeCoster, "Developing measurement scales of organizational and issue legitimacy: a case of direct-to-consumer advertising in the pharmaceutical industry," Journal of Business Ethics, vol. 137, no. 2, pp. 405-413, 2016. 
[5] E. M. A. Ahmed, "A hydrologic-economic-agronomic model with regard to salinity for an over-exploited coastal aquifer," Journal of Geosciences, vol. 12, no. 12, pp. 1-12, 2019.

[6] W. L. Baloch, R. A. Khushnood, S. A. Memon, W. Ahmad, and S. Ahmad, "Effect of elevated temperatures on mechanical performance of normal and lightweight concretes reinforced with carbon nanotubes," Fire Technology, vol. 54, no. 5, pp. 1331-1367, 2018.

[7] H. X. Chen, Y. T. Chen, and L. Yang, "Intelligent early structural health prognosis with nonlinear system identification for RFID signal analysis," Computer Communications, vol. 157, pp. 150-161, 2020.

[8] P. Di Girolamo, A. Behrendt, and V. Wulfmeyer, "Spaceborne profiling of atmospheric thermodynamic variables with Raman lidar: performance simulations," Optics Express, vol. 26, no. 7, pp. 8125-8161, 2018.

[9] A. Edrees, H. Abdelhamed, and M. L. Lawrence, "Construction and evaluation of type III secretion system mutants of the catfish pathogen Edwardsiella piscicida," Journal of Fish Diseases, vol. 41, no. 5, pp. 805-816, 2018.

[10] M. Guo and N. Arunkumar, "Construction of employee training program evaluation system of three exponential forecast based on sliding window," Cluster Computing, vol. 22, no. 3, pp. 6865-6870, 2019.

[11] S. Adler, M. Campion, and E. D. Pulakos, "Getting rid of performance ratings: genius or folly? a debate," Industrial and Organizational Psychology-Perspectives on Science and Practice, vol. 9, no. 2, pp. 219-252, 2016.

[12] H. Aguinis, Y. H. Ji, and H. Joo, "Gender productivity gap among star performers in stem and other scientific fields," Journal of Applied Psychology, vol. 103, no. 12, pp. 1283-1306, 2018.

[13] D. W. Bracken, D. S. Rose, and A. H. Church, "The evolution and devolution of 360 degrees feedback," Industrial and Organizational Psychology-Perspectives on Science and Practice, vol. 9, no. 4, pp. 761-794, 2016.

[14] J. L. Pereira and J. O. E. Sa, "Process-based information systems development: taking advantage of a componentbased infrastructure," Business Systems Research Journal, vol. 8, no. 2, pp. 71-83, 2017.

[15] A. Trigo, J. Varajao, and N. Gonzalvez-Gallego, "Enterprise information systems adoption in iberian large companies: motivations and trends," Managing Adaptability, Intervention, and People in Enterprise Information Systems, vol. 32, no. 1, pp. 204-228, 2011.

[16] J. E. Varajao, "A new process for success managementbringing order to a typically ad-hoc area," Modern Project Management, vol. 5, no. 3, pp. 94-99, 2018.

[17] L. Abdullah and N. Zulkifli, "Integration of fuzzy AHP and interval type-2 fuzzy dematel: an application to human resource management," Expert Systems with Applications, vol. 42, no. 9, pp. 4397-4409, 2015.

[18] F. Sadile, A. Bernasconi, F. Carbone, F. Lintz, and G. Mansueto, "Histological fibrosis may predict the failure of core decompression in the treatment of osteonecrosis of the femoral head," International Journal of Surgery, vol. 44, pp. 303-308, 2017.

[19] S. Okazaki, N. Satoshi, H. Matsumoto et al., "TLR4 stimulation and corticosteroid interactively induce osteonecrosis of the femoral head in rat," Journal of Orthopaedic Research, vol. 34, no. 2, pp. 342-345, 2016.

[20] K. Kamikawa, K. Takahashi, T. Shigemura et al., "Incidence of osteonecrosis associated with corticosteroid therapy among different underlying diseases: prospective MRI study," Rheumatology, vol. 50, no. 11, pp. 2023-2028, 2011.

[21] N. T. Issa, S. W. Byers, and S. Dakshanamurthy, "Big data: the next Frontier for innovation in therapeutics and healthcare," Expert Review of Clinical Pharmacology, vol. 7, no. 3, pp. 293-298, 2014.

[22] X. Wu, X. Zhu, G. -Q. Wu, and W. Ding, "Data mining with big data," IEEE Transactions on Knowledge and Data Engineering, vol. 26, no. 1, pp. 97-107, 2014.

[23] P. Alessio, C. Peter, and H. Robert, "Prolonging the lifetime of old steel and steel-concrete bridges: assessment procedures and retrofitting interventions," Structural Engineering International, vol. 29, no. 4, pp. 507-518, 2019.

[24] C. Pellegrino, A. Pipinato, and C. Modena, "A simplified management procedure for bridge network maintenance," Structure and Infrastructure Engineering, vol. 7, no. 5/6, pp. 341-351, 2011.

[25] T. Fischer and C. Krauss, "Deep learning with long short-term memory networks for financial market predictions," European Journal of Operational Research, vol. 270, no. 2, pp. 654-669, 2018.

[26] H. Hu, L. Tang, S. Zhang, and H. Wang, "Predicting the direction of stock markets using optimized neural networks with google trends," Neurocomputing, vol. 285, no. 12, pp. 188-195, 2018.

[27] C. Krauss, X. A. Do, and H. Nicolas, "Deep neural networks, gradient-boosted trees, random forests: statistical arbitrage on the S\&P 500," European Journal of Operational Research, vol. 259, no. 2, pp. 689-702, 2017.

[28] M. Ballings, D. den Poel, N. Hespeels, and R. Gryp, "Evaluating multiple classifiers for stock price direction prediction," Expert Systems with Applications, vol. 42, no. 20, pp. 7046-7056, 2015.

[29] M. Nofer and P. Oliver Hinz, "Using twitter to predict the stock market," Business \& Information Systems Engineering, vol. 57, no. 4, pp. 229-242, 2015.

[30] F. Ahmad, N. A. Mat Isa, Z. Hussain, M. K. Osman, and S. N. Sulaiman, "A GA-based feature selection and parameter optimization of an ANN in diagnosing breast cancer," Pattern Analysis \& Applications: PAA, vol. 18, no. 4, pp. 861-870, 2015.

[31] M. J. Mokarram, T. Niknam, J. Aghaei, M. Shafie-khah, and J. P. S. Catalao, "Hybrid optimization algorithm to solve the nonconvex multiarea economic dispatch problem," IEEE Systems Journal, vol. 13, no. 3, pp. 3400-3409, 2019.

[32] X. Li, Y. Wang, Q.-H. Wang, Y. Li, and X. Zhou, "Modified integral imaging reconstruction and encryption using an improved SR reconstruction algorithm," Optics and Lasers in Engineering, vol. 112, no. 6, pp. 162-169, 2019. 